\title{
ÉRASE, ES Y SERÁ... APRENDER A SER EN LAS ENCICLOPEDIAS PARA NIÑOS
}

\author{
Elvira LUENGO GASCÓN \\ Universidad de Zaragoza \\ eluengo1@unizar.es
}

\begin{abstract}
No sé si la literatura lleva a una mayor felicidad, pero sí estoy segura de que lleva a una mayor conciencia de nuestra presencia en el mundo.
\end{abstract}

María Teresa Andruetto

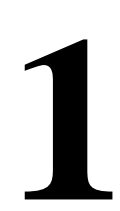

\section{Introducción}

No se trata de extendernos en los orígenes, el desarrollo y la evolución de las enciclopedias a lo largo de la historia, sin embargo, creemos necesario definirlas brevemente, mencionando algunos hitos, para introducir, posteriormente, la problemática de algunas de ellas editadas en el siglo XX. Dar a conocer tres o cuatro destacadas enciclopedias de literatura para niños y adolescentes en diferentes países europeos, y la vinculación que se origina entre ellas, consolida nuestro propósito en este artículo. Son obras publicadas en lengua inglesa, italiana y española para educar a un público infantil que atraviesa momentos históricos, ideologías e intereses políticos diversos. L'Enciclopedia dei ragazzi, italiana, nace como traducción y adaptación de la Encyclopedia of Children inglesa, publicada en Londres. La Scala d'oro italiana, a su vez, es la fuente de la que parte El libro de oro de los niños publicado en México en lengua española bajo la dirección literaria del escritor español Benjamín Jarnés, exiliado allí en 1939. Los seis volúmenes que componen la enciclopedia de El libro de oro de los niños (un mundo maravilloso para la infancia) llegan a editarse finalmente con enorme difusión en Hispanoamérica trasladando y difundiendo así la cultura y el patrimonio europeo. Se pone en juego, de esta manera, una transferencia del saber enciclopédico destinado a la infancia para (de)construir a través de la enseñanza del arte y el conocimiento humano una identidad - ¿nacional, transnacional, mundial?- desde una polifonía de lenguas y de culturas.

Destacamos el significado social y cultural que tiene la lectura en el proceso de socialización y transmisión cultural a lo largo de las generaciones, los procesos educativos y la generación de redes sociales (Yubero y Larrañaga, 2010). Como indica Larrosa:

Pensar la lectura como formación implica pensarla como una actividad que tiene que ver con la subjetividad del lector: no sólo con lo que el lector sabe, sino con lo que el lector es. Se trata de pensar la 
lectura como algo que nos forma (o nos de-forma, o nos trans-forma), como algo que nos constituye o nos pone en cuestión en aquello que somos (Larrosa, 1996: 25).

Así pues, es nuestro mundo interior, en su totalidad, el que acoge, incorpora, amplía y enriquece cualquier lectura, «en una experiencia que no admite ni la impostura ni la falsedad. Algo que crece y se desarrolla desde nuestro propio ser, en un aparente soliloquio poblado de innumerables voces, en una proximidad absoluta, que requiere, tantas veces, la más celosa de las reservas» (Basanta Reyes, 2005: 191).

Es tal el valor que Mèlich concede a la lectura de un libro, que la compara con acontecimientos tan importantes como el nacimiento o la muerte de un amigo; la lectura es un acontecimiento que «puede romper nuestra situación en el mundo y obligarnos a un replanteamiento total de nuestro periplo existencial» (Mèlich, 2006: 117).

\section{Algunas consideraciones sobre Literatura para niños}

María Teresa Andruetto señalaba en su libro Hacia una literatura sin adjetivos (2009) que la literatura se define por la multisignificación y la ambigüedad.

Andruetto escribió una filosofía literaria con una profunda introspección sobre la literatura, el oficio del escritor y el lazo con el lector. Sin dejar de lado en ningún momento la cotidiana pelea contra la literatura y sus atributos (título de Saer del cual se ha parafraseado el del libro). Y cuando el lector se desliza por el texto escrito va descubriendo un mundo novedoso porque esta filosofía literaria que profundiza sobre la materialidad del texto (al decir de Graciela Montes) es poética a la vez que discursiva, es seductora, convincente y por encima de todo es literatura en esencia (Perriconi, 2009).

Solemos otorgar al relato una dimensión esencialmente verbal. Pero tan falseada noción forma parte de nuestros prejuicios logocéntricos. La imagen ha asumido funciones narrativas desde antes que apareciera la escritura. Basadas en un guión cultural implícito que las hacía legibles, las inscripciones prehistóricas ya transmitían una intriga. Sin ir tan lejos, pueden rastrearse desde la Antigüedad abundantes testimonios de cómo se han ido forjando y cómo han ido variando en función de las épocas y los códigos sobre los que se ha asentado esta «narrativa inscriptiva». El relato se genera desde dos vías, una como creación-recepción y la otra como difusión. Nos instalamos ahora en las redes del futuro. Los nuevos formatos y géneros en la Literatura Infantil y Juvenil, el libro álbum, el cómic, la novela gráfica, el relato con imágenes, incluso sin texto, los libros juego, los pop-ups, el libro móvil, los libros de artista, se imponen en las corrientes actuales y es la imagen la que protagoniza el relato.

La imaginación debe presidir la educación, como señala Gianni Rodari en su Gramática de la fantasía: introducción al arte de inventar historias; por ello, reconsiderar los modelos propuestos a los niños debería tener prioridad en cualquier manifestación artística y literaria destinada a la infancia. El pedagogo italiano entiende la creatividad como

[...] sinónimo de «pensamiento divergente», o sea, capaz de romper continuamente los esquemas de la experiencia. Es «creativa» una mente siempre activa, siempre haciendo preguntas, descubriendo problemas donde los otros encuentran respuestas satisfactorias, a sus anchas en las situaciones fluidas en las que otros barruntan sólo peligros, capaz de juicios autónomos e independientes (incluso del padre, del profesor y de la sociedad), que rechaza lo codificado, que vuelve a manipular objetos y conceptos sin dejarse inhibir por los conformismos. Todas estas cualidades se manifiestan en el proceso creativo (Rodari, 2002: 157). 
El pensamiento divergente, según Rodari, es el que sea capaz de construir algo nuevo, de crear en todos los campos de la cultura y de las ciencias. Se muestra, de esta manera, la necesidad de educar literariamente en la creatividad, desarrollar la imaginación en los niños y jóvenes que han de construir su propia identidad y acometer los retos vitales en todos los ámbitos. Educar a los niños en la fantasía, no para que sean capaces de reproducir e imitar sino de crear, de inventar. Innovación es invención, aunque se sustente sobre la experiencia adquirida; cuanto mayor sea el enriquecimiento vital, experiencial, de cada niño, mayores posibilidades poseerán de que su imaginación y su capacidad de crear sea mayor. «Es posible una educación a través de la "creatividad"», señalaba Rodari en su Gramática de la Fantasía (2002: 157).

En Rodari se comienza a gestar este estudio, de crear una teoría de la Fantástica, hacia los años cuarenta del siglo pasado. Aboga por una educación estética en el hombre y en el niño (citando a Schiller) que debe incluir el juego. La actividad artística es la que puede desarrollar en el niño un modo de experiencia integral. Para desarrollar el pensamiento lógico infantil es necesaria la imaginación. El pedagogo se expresa en estos términos:

[...] entre una escuela muerta y una escuela viva, el rasgo distintivo más auténtico es precisamente éste; la escuela para «consumidores» está muerta, y fingir que está viva no sirve para ahuyentar los olores de su putrefacción (que está a la vista de todos); una escuela viva y nueva puede ser sólo una escuela para «creadores». Es como decir que no se puede estar ya como «alumnos» o como «profesores», sino como hombres íntegros (Rodari, 2002: 159).

De manera que, en este clima, Rodari, como maestro que fue, encuentra la figura del maestro de suma importancia, fundamental, y describe la concepción que tiene de él:

El maestro se transforma en un «animador». En un promotor de creatividad. Ya no es aquel que transmite un saber brillante y acabado, un bocado por día; un domador de borriquillos; un amaestrador de focas. Es un adulto que está con los chavales para expresar lo mejor de sí mismo, para desarrollar también en sí mismo los hábitos de la creación, de la imaginación, del compromiso constructivo en una serie de actividades que ya se consideran equivalentes; las de producción pictórica, plástica, dramática, musical, afectiva, moral (valores, normas de convivencia), cognoscitiva (científica, linguística, sociológica), técnicoconstructiva, lúdica, «ninguna de las cuales ha de entenderse como entretenimiento o distracción con respecto a otras que se consideran más dignas» (Rodari, 2002: 159).

Así pues, la herencia literaria de la que partimos, nuestro legado y nuestra tradición, sirve de soporte necesario para lograr la identificación y que cada persona pueda apropiarse de las necesarias bases identitarias para construir su propia individualidad. Por tanto, es interesante estudiar y conocer algunas muestras de esa literatura que nutre a los jóvenes, como es el caso de las diferentes colecciones, series y enciclopedias de nuestro patrimonio europeo. Como ejemplo, se presenta una enciclopedia para niños editada en América y dirigida por el escritor aragonés Benjamín Jarnés, aunque sus orígenes y sus contenidos, en parte, son profundamente europeos: El libro de oro de los niños (un mundo maravilloso para la infancia). Enciclopedia heredera de otras que se presentan aquí también. 


\section{El saber enciclopédico: cultura institucional/cultura popular}

El estudio de las colecciones, series y enciclopedias literarias para niños nos lleva a vislumbrar las manifestaciones culturales entre dos polos: entre la cultura institucional y la cultura popular. Se expone el recorrido de varias de estas series, colecciones o enciclopedias, que nacen en el corazón de Europa y finalizan su periplo en las generaciones de jóvenes americanos de lengua española desde los años cuarenta hasta varias décadas posteriores. Es interesante conocer la vía de transmisión cultural desde La Scala d'oro italiana hasta El libro de oro de los niños publicado en México en lengua española. Este recorrido revela la influencia cultural y el flujo del pensamiento literario europeo hacia la cultura americana a través de los escritores exiliados españoles. El libro de oro de los niños representa la educación literaria que se muestra como modelo educativo de cultura institucional dirigida a grupos populares. Mediante la magnífica enciclopedia que se edita en México, Argentina y otros países de Hispanoamérica, que tuvo numerosas reediciones en los años siguientes, se tiende un puente de comunicación intercultural para las corrientes literarias de vanguardia y el pensamiento postmoderno europeo que facilitó la transmisión de los clásicos europeos. Nexo que aprovecha el intercambio de la gran riqueza intelectual de los dos continentes fuertemente anclada en una tradición de siglos. Desde la literatura dedicada a los niños, se ejerce una transferencia cultural, artística, literaria y de pensamiento que se establece entre ambos continentes y representa un acercamiento entre la identidad europea, que trasciende más allá de este continente, allende el Atlántico, y los lectores jóvenes de la América de habla hispana en el siglo XX. No se difunde sólo la cultura española, El libro de oro de los niños acumula un patrimonio histórico, cultural, artístico y literario de una cuidada selección europea con criterios vanguardistas de la postmodernidad avanzada que ostentó siempre el director de esta obra, Benjamín Jarnés. Jarnés fue un humanista moderno que buscó siempre recuperar una infancia perdida a lo largo de su brillante carrera de escritor sumergiéndose en los libros. Y, como Sherezade, afirmaba: «yo salvé mi vida narrando».

\section{1. Intercambios culturales}

La Scala d'oro publicada originalmente en italiano por la Unione Tipografico-Editrice Torinese de Turín, en Italia, fue dirigida por Vicenzo Errante y Fernando Palazzi. Varias secciones de esta obra constituyen una adaptación a la lengua española en la enciclopedia dirigida literariamente por Jarnés y artísticamente por Luis Doporto con el nombre que se ha señalado. Se publica su primera edición en 1943, en México, con una tirada de quince mil ejemplares en seis volúmenes. La enciclopedia dirigida por Jarnés alcanzó hasta dieciséis capítulos en cada volumen. Tuvo numerosas reediciones en América, (que detallamos más adelante), y constituyó un texto de referencia en la educación de los niños y jóvenes de habla española del continente americano.

\section{2. La Scala d'oro}

La Scala d'oro, publicada por editorial Utet de Turín, desde 1932 a 1945, destaca por el alto nivel cualitativo de títulos, y también de las ilustraciones, y por no ajustarse a las directivas del régimen 
fascista. Es un ejemplo de lo que se puede definir como una «zona franca» en el interior de las censuras y de los controles de la dictadura, que permite ampliar el conjunto de las reflexiones sobre la producción para niños y jóvenes en una fase crucial de la historia de Italia como la marcada por el fascismo. Como resultados, tras el estudio profundo de esta obra, puede decirse que se podrían definir, en torno a la historia de una obra importante como La Scala d'oro, los cambios del imaginario infantil, los valores y los contenidos educativos destinados a niños; en suma, la peculiaridad de una oferta de lectura que no alimentaba al régimen.

Giulia Aiolfi, en La Scala d'oro" della UTET: una collana per ragazzi durante il fascismo (1932-36), que recoge su tesis doctoral, confirma que se trata de «un piccolo tesoro èconservato negli archivi dell'Archivio per l'immagine e la comunicazione editoriale (APICE) dell'Università degli studi di Milano: si tratta della collezione completa dei volumi della collana per l'infanzia La Scala d'oro della casa editrice torinese UTET» ${ }^{1}$.
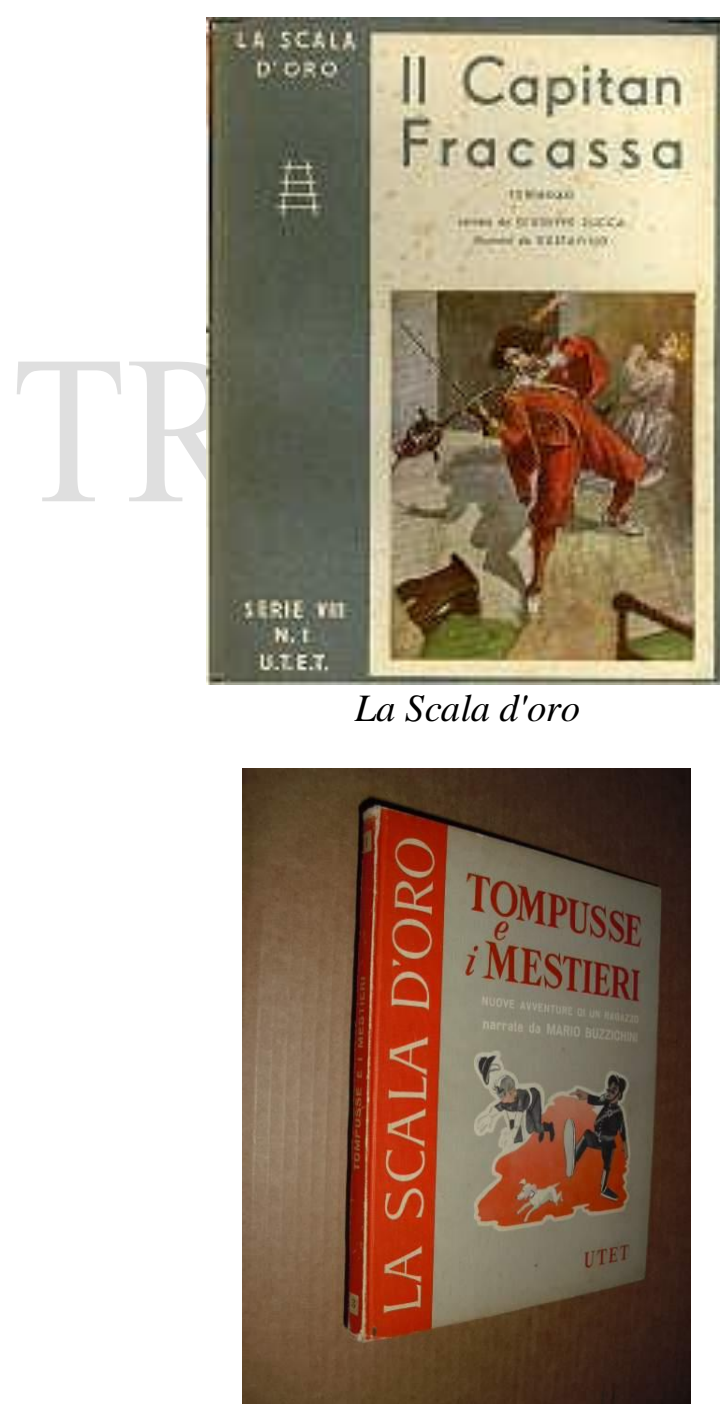

La Scala d'oro. Tompusse e i Mestieri. Nuove avventure di un ragazzo

\footnotetext{
${ }^{1}$ «La collana appartiene alla collezione Reggi, la raccolta privata dell'attore Sergio Reggi, considerata una delle più importanti dell'editoria italiana del ' 900 e di recente acquisita da APICE. In merito cfr. L. BRAIDA, I ragazzi di Reggi agli archivi di Apice, "WUZ. Storie di editori, autori e libri rari", 2004, n. 3, pp. 47-51».
} 


\section{3. L'Enciclopedia dei ragazzi}

En 1922 Arnoldo Mondadori publica, traduciéndola del inglés, L'Enciclopedia dei ragazzi (La Enciclopedia de los niños), confirmando la vocación de invertir en el sector escolástico-educativo, que será uno de los elementos de afirmación de la editorial, presente desde sus principios. Fundada en 1907, la primera columna que se edita en 1911 dedicada a la lectura infantil se llamaba «La lámpara». Esta atención al mundo de la literatura infantil era síntoma de una nueva sensibilidad hacia los niños; por un lado, como un nuevo segmento del mercado (no solo editorial) y por otro, se presenta a los niños como destinatarios de cuidados y atenciones que pronto se convertirán en naturaleza política. No es arriesgado, entonces, elegir la editorial Mondadori, destinada a reafirmarse, entre la dos guerras, como la principal empresa del sector en Italia y a convertirse en uno de los colosos más importantes de la publicación nacional a lo largo del siglo pasado, ocupando un lugar privilegiado para observar los cambios y la continuidad en el recorrido de la literatura infantil y en la constitución de un imaginario para la infancia italiana del siglo XX.

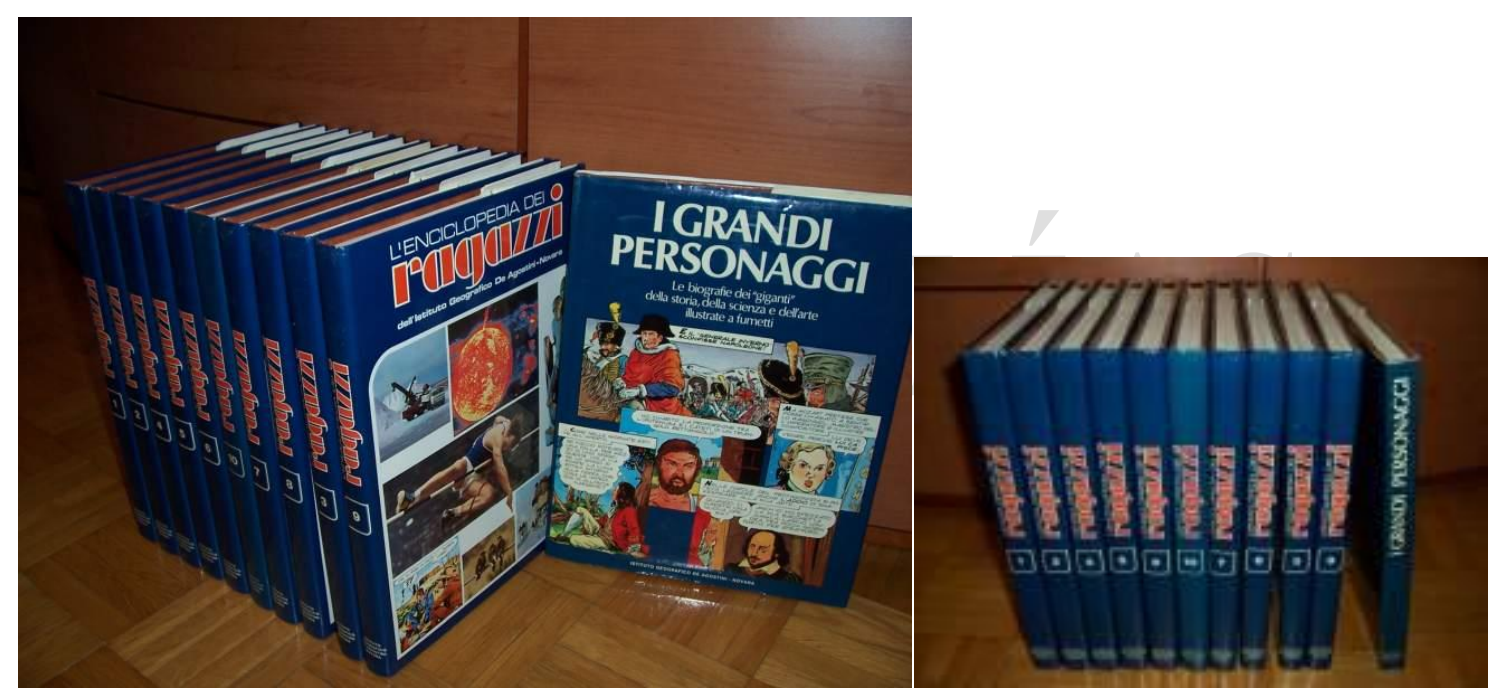

Al respecto, L'Enciclopedia dei ragazzi se presta de manera ejemplar para guiar una investigación comparando los diferentes momentos históricos en los que ha sido reeditada y actualizada. Esta obra infantil ha sido objeto de muchas publicaciones y cada vez se trataban de actualizar los contenidos específicos y también se adaptaban al cambiante clima político y pedagógico. Nacida como traducción del inglés, se afirma en la época del idealismo pedagógico (de 1923, en la reforma de Giovanni Gentile) y se extiende en la Italia fascista, para encontrarse después en el clima de la posguerra, en la Italia republicana y democrática. Para absorber, por fin, esta Enciclopedia los cambios pedagógicos y educativos de los años sesenta y setenta y llegar hasta las últimas ediciones de los primeros años noventa.

A través de los análisis de estas dos obras italianas se puede reconstruir la imagen de la infancia que se ha ido perfilando en la Italia del siglo Xx; los temas, los valores y la prospectiva educativa implícita en L'Enciclopedia dei ragazzi y en La Scala d'oro, es propuesta a los jóvenes lectores, así 
como el cambio de los contenidos y del público al que van destinados. Los destinatarios de principios de siglo comienzan por ser reducidas elites sociales para convertirse más tarde en una lectura dirigida a las masas.

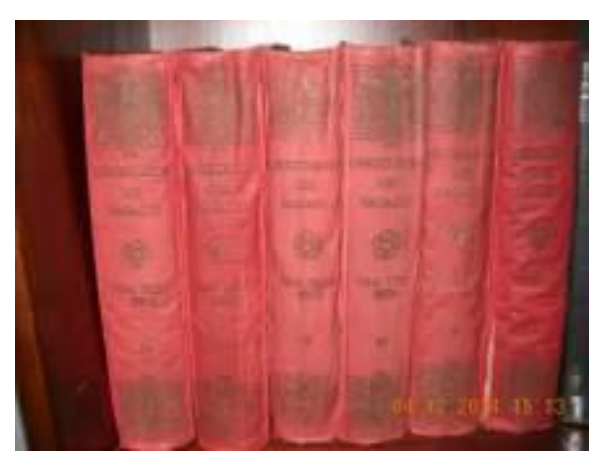

Enciclopedia de los Niños

Traducción y adaptación de Arthur Mee, Enciclopedia de los Niños, Londres. Obra encuadernada en tela roja. Seis volúmenes originales, 1920. Editorial Mondadori. A. Milán.

Es interesante estudiar los pormenores internos de la publicación (creadores, colaboradores, estrategias de mercado, relaciones con la política....) y las numerosas reediciones destacando los cambios y la continuidad en el contexto educativo, histórico y literario en el que aparece. El análisis comprende dos niveles. El primero, de naturaleza esencialmente textual, relacionado con los contenidos (comprendidos los apartados iconográficos) de la Enciclopedia; el segundo referente a los documentos presentes en la Fundación Mondadori de Milán, que pueden dar cuenta de los diferentes contextos (es decir, el interior de la historia cultural, social y política italiana) que la obra ha atravesado en su larga vida editorial.

\section{4. La pequeña memoria recobrada. Libros infantiles del exilio del 39}

Benjamín Jarnés, clásico actual, vanguardista y en la atalaya de las corrientes europeas dirigió en México dos enciclopedias de Literatura, una de ellas de Literatura Juvenil, dedicada a la infancia, editada en seis volúmenes con magníficas ilustraciones de los mejores artistas del momento. Una auténtica joya, El libro de oro de los niños (un mundo maravilloso para la infancia), una obra que ha permanecido olvidada, sin embargo, se ha recordado esta pérdida en La pequeña memoria recobrada. Libros infantiles del exilio del 39, catálogo editado por el Ministerio de Educación en marzo de 2008. En el prólogo, Alejandro Tiana Ferrer, Secretario General de Educación, reconoce el trabajo llevado a cabo por Ana Pelegrín, y afirma que «el interés del libro radica en que a través de sus sucesivos capítulos se analiza un sector de la literatura infantil y juvenil tan desconocido como digno de recuperación...» (Tiana Ferrer, 2008: 5). Digno de recuperación, porque no sólo estamos hablando de algunos de nuestros mejores escritores en la primera mitad del siglo XX, sino porque muchos de ellos continuaron realizando propuestas innovadoras y enlazaron el pasado literario con las nuevas tendencias que se difundían en Europa y América en esos años. El Secretario General de Educación insiste, en este prólogo, en que «la memoria de nuestra educación y de nuestra cultura infantil debería ocupar un espacio privilegiado. [...] A través de esas memorias individuales o colectivas estamos en 
mejor situación para recuperar parte de nuestro pasado, olvidado, silenciado». En estas palabras se refleja claramente el caso de Benjamín Jarnés y de El libro de oro de los niños, por lo que avalan el deseo de que vea la luz de nuevo este valioso testimonio literario, artístico. Nos apropiamos de nuevo de las últimas recomendaciones del Secretario General en el prólogo cuando anima al lector a adentrarse en las páginas del libro que prologa «a saborear tantas historias, a disfrutar de un pasado tan denso. Y por qué no, a lanzarse a la recuperación y la lectura de las obras que aparecen tan cuidadosamente catalogadas. La aventura vale la pena» (Tiana Ferrer, 2008: 6). La enciclopedia dirigida por Jarnés aparece en este catálogo. Asimismo, la amplia y premiada obra de Antoniorrobles dedicada a la infancia, la serie de Aleluyas de Rompetacones que es una colección de cuentos también está presente en el catálogo de La pequeña memoria recobrada. Libros infantiles del exilio del 39 (2008: 211-219)². Jarnés publicó numerosas páginas elogiosas en su crítica periodística en los años cuarenta del exilio americano a los libros de Antoniorrobles.

Luis Ahumada Zuaza en un ensayo sobre «Teatro Infantil y Juvenil Español. Las vanguardias españolas del siglo $\mathrm{XX»} \mathrm{estudia} \mathrm{la} \mathrm{producción} \mathrm{literaria} \mathrm{para} \mathrm{niños} \mathrm{de} \mathrm{algunos} \mathrm{autores} \mathrm{como}$ Antoniorrobles, Dieste, Casona, y las Misiones Pedagógicas:

\begin{abstract}
En los años treinta comenzará su producción literaria Antonio Robles Soler (Antoniorrobles), el cual será reconocido como el verdadero introductor de las vanguardias dentro de la literatura infantil y juvenil española; incluso se ha llegado a afirmar que es el padre de la literatura infantil contemporánea española. Conocido más por su narrativa infantil, también escribe teatro para ellos con su característico humor superrealista (El príncipe no quiere ser niño. ¡El toro a escena!). Será, a su vez, el director durante los primeros años treinta de El perro, el ratón y el gato (Semanario de las niñas, los chicos, los bichos y los muñecos), brillante revista abierta a tendencias modernas y vanguardistas, en la cual escribirían para los niños firmas como Miguel Mihura, Elena Fortún o Ramón Gaya, acercándoles tendencias como el Absurdo. En ella había un apartado titulado «Teatro del Perro, el Ratón y el Gato», más conocido como «Teatro PRG», en el que se publicaron pequeñas piezas dramáticas dignas, quizás, del mejor Samuel Beckett (Ahumada Zuara, 2015: 22-23).
\end{abstract}

Un trabajo de sumo interés acerca de la producción literaria para niños en México es el coordinado por Pedro Cerrillo y María Teresa Miaja publicado en 2013 La literatura infantil y juvenil española en el exilio mexicano. Se ha llevado a cabo en esta obra una investigación de carácter histórico, literario y documental, que ha tenido como objetivo recoger, seleccionar, documentar y estudiar todo el material disponible de y sobre la literatura infantil y juvenil que los españoles crearon en el exilio mexicano, tanto en lo que respecta a las obras originales como en lo referente al campo de las aportaciones críticas y teóricas. Se explora no sólo la creación literaria sino también la labor de ilustradores, editores, impresores y maestros exiliados, destacando las implicaciones sociológicas y educativas de aquel exilio y la importancia de una tradición literaria que en muchos casos era continuación de la que se estaba haciendo en España antes del inicio de la Guerra Civil. La lectura de las páginas de este estudio pone de manifiesto la vitalidad de la literatura infantil y juvenil que los españoles crearon durante el exilio en México y la importancia que le concedía la comunidad exiliada,

\footnotetext{
${ }^{2}$ Antoniorrobles publica en 1939, en México, veinte libros con el nombre de Aleluyas de Rompetacones, ilustrados todos ellos por Ramón Peinador.
} 
no sólo como medio de entretenimiento sino también como medio de educación y mantenimiento de una tradición literaria y plástica rota por la guerra (Cerrillo y Miaja, 2013).

\section{5. Años setenta: contribución hispanoamericana en la literatura infantil en España}

El desarrollo de la literatura infantil en España experimenta un despegue a partir de la reforma educativa de 1970 promovida por la llamada ley Villar Palasí. La influencia hispanoamericana contribuyó al desbloqueo del sistema educativo español que desde 1939 hasta mediados de los años setenta permaneció lejos de la renovación y de las influencias extranjeras, a causa de su sistema político dictatorial.

\section{Para Teresa Colomer,}

Los autores surgidos del mayo del 68, por decirlo de forma emblemática, ofrecerán un nuevo tipo de libro infantil que supone un intento, más o menos deliberado, de renovar los valores y modelos sociales habituales en este tipo de literatura. Son precisamente estas nuevas tendencias las que serán masivamente incorporadas a nuestro país mediada ya la década de los setenta y las que caracterizarán la evolución de la producción propia de estos últimos años (Colomer, 1991: 16).

Juan Cervera analiza en «La contribución hispanoamericana al desarrollo del estudio de la literatura en España» el marco de la renovación en España de la enseñanza, de los profesores y de la propia Literatura Infantil y expone los cauces y las causas:

No puede negarse la afluencia de educadores europeos, españoles y norteamericanos que coincidían, en el momento más que ahora, en el vasto continente hispanoamericano, unas veces por motivos sociopolíticos, otras, como aportación de las misiones católicas. Todos ellos, naturalmente, contribuyeron a dar a la cultura hispanoamericana un carácter de crisol más acentuado que en España (Cervera, 1992: 300).

Los movimientos culturales, de personas y de corrientes se suceden en direcciones opuestas a lo largo del tiempo, de ahí que se pueda afirmar este ir y venir como otra de las causas de influencia en el panorama de la literatura para niños:

Al contar con una especie de pasillo natural entre España e Hispanoamérica, en trasiego de ida y vuelta, ahora estimulado por la reforma, no sólo llegan a España ideas en las que los hispanoamericanos nos habían adelantado, sino que se da el caso curioso de autores españoles de literatura infantil o relacionados con ella, como Alejandro Casona, Antonio Robles, Elena Fortún, Herminio Almendros o Eduardo Martínez Torner, todos ellos españoles, que, a partir de este momento y por vía bibliográfica, regresarán a España de la que estaban ausentes (Cervera, 1992: 300).

\section{Benjamín Jarnés en Europa}

\section{1. Francia}

Recordamos en este punto, la exposición que permaneció en París, de octubre de 2008 a abril de 2009, en la Biblioteca Nacional de Francia, Babar, Harry Potter et compagnie. Livres d'enfants d'hier et d'aujourd'hui como confirmación de la importancia que se le otorga también en Francia a la

\footnotetext{
${ }^{3}$ Babar, Harry Potter et compagnie. Livres d'enfants d'hier et d'aujourd 'hui, es el catálogo de la exposición en la BNF de 2008-20009, magnífico libro con estudios sobre la Literatura Infantil y Juvenil en Francia muy recomendable. Al igual que La pequeña memoria recobrada. Libros infantiles del exilio del 39, para la Literatura Infantil y Juvenil en lengua española
} 
literatura infantil y juvenil, a su pasado y a su recuperación, y el lugar que ocupa entre las prioridades de la cultura.

L'adjectif «documentaire», souvent substantivé, est couramment employé par les éditeurs français pour la jeunesse afin de désigner des ouvrages à finalité éducative, non scolaires, même s'ils flirtent, volontiers avec le parascolaire (Hache-Bissette, 2008: 356).

Los anglosajones prefieren utilizar la expresión de «non fiction» o dicho de otra manera «vrai», verdadero, cierto, en español. Al extrapolar, se observa por un lado la función referencial, de información y de educación, por otro lado la función de emoción. Esta dicotomía parece a primera vista simple y cómoda, sin embargo, excluye numerosos libros para niños que se sitúan en la intersección de los dos géneros.

Le «documentaire» est protéiforme: il a, au fil du temps et des modes, pris de multiples aspects; l'objectif étant certes toujours de transmettre de manière optimale un savoir mais aussi de séduire le jeune lecteur et surtout le (moins jeune) prescripteur-acheteur, qu'il soit parent, enseignant ou bibliothécaire (Hache-Bissette, 2008: 356)

Se plantea el debate entre realismo y ficción o didactismo y creación. Este debate corresponde igualmente a un tipo de libros, o de literatura didáctica, que abordamos en estas páginas, se trata de las enciclopedias. El saber enciclopédico, el enciclopedismo, las colecciones del pasado, que formaron parte de la pedagogía de los siglos pasados y en los que Francia se inscribe en primera página por acuñar el término, como señalábamos anteriormente. Los manuales escolares que transmitían a los niños los conocimientos indispensables de la humanidad eran pesadas enciclopedias en las cuales la imagen convertía en algo más atractivo los contenidos didácticos a menudo áridos.

Entre los ilustres antepasados del libro documental para los jóvenes, se conoce l'Orbis Sensualium Pictus, un abecedario ampliamente ilustrado, realizado por un pedagogo, Johann Amos Komensky, llamado Comenius, y publicado en Nuremberg en 1658. En los siglos XVIII, XIX y XX aparecieron en toda Europa diferentes series de Enciclopedias con un número variable de volúmenes que recogían el saber de las diversas ciencias y técnicas para satisfacer a un nuevo lector, ávido de saberes (Hache-Bissette, 2008). Este espectacular desarrollo de las enciclopedias venía a contribuir a la alfabetización de la población. En Francia, la tendencia a las colecciones o el enciclopedismo por la imagen aparece desde la segunda mitad del siglo XVIII, se renovó en los años de 1950 con la importación por las ediciones Cocorico de colecciones americanas abundantemente ilustradas. La gran novedad de la edición enciclopédica es su «miniaturización», es decir su paso al formato bolsillo.

Pierre Marchand lanza en 1986 la colección «Découvertes Gallimard» (Hache-Bissette, 2002) que aporta el color en la enciclopedia de bolsillo. Colección destinada a los adolescentes en principio, sin embargo fue rápidamente adoptada por los adultos.

La conexión de Jarnés con la literatura francesa es muy extensa. Giraudoux, Stendhal, Aloysius Bertrand, Baudelaire, Verlaine y otros autores han ocupado las páginas de los libros jarnesianos a

editado en 2008 y acompañado de un CD del catálogo completo. En ambas obras las imágenes tienen un gran peso y son de una gran calidad. 
modo de ensayos, prólogos o artículos en la prensa. Jarnés, en 1939, estuvo en Limoges unos meses y en París, allí escribió sobre sus impresiones en sus extensos cuadernos o diarios y también tradujo obras de autores franceses. Antes del exilio de Jarnés en el 39, Marcel Brion publicaba reseñas de las obras jarnesianas en revistas francesas desde París y divulgaba la obra del aragonés en Italia. El estudio de la relación de ambas literaturas con el aragonés es sobradamente interesante. En el Colegio de España de París se encargaban obras para esta biblioteca (en 1936) como por ejemplo la biografía novelada Sor Patrocinio. La monja de las llagas que Jarnés publicó ${ }^{4}$. León Sánchez Cuesta, el llamado librero del veintisiete, se encargaba de proporcionar ejemplares jarnesianos para esta biblioteca en París, que fue y es centro de acogida cultural, de investigación, de reunión de la intelectualidad española.

El estudio comparado de la obra de Jarnés y de la literatura francesa resulta altamente relevante, destacamos a Jean Giraudoux, autor admirado por el español y buen conocedor de sus obras (Ondine, Suzanne et le Pacifique, Littérature etc...) y Stendhal (Le Rouge et le noir) por su enorme influencia de la literatura francesa. Stendhal, es autor muy querido por Jarnés; en homenaje al héroe romántico de Le Rouge et le noir escribió el aragonés Lo rojo y lo azul, novela autobiográfica. La admiración del aragonés hacia estos dos autores fusiona las vanguardias con Giraudoux («Giraudoux español» se le denominó a Jarnés ${ }^{5}$ ) y el romanticismo con Stendhal.

\section{2. Italia}

Jarnés conoce la literatura italiana y a los escritores contemporáneos italianos y mantiene un gran interés hacia las novedades literarias. El libro de Oro de los niños, apareció este nombre en una edición, con este mismo nombre, en Turín (siglo XIX), anterior a la que Jarnés publicó en Buenos Aires (1943), en la editorial Acrópolis.

El autor francés Henry Beyle, con el seudónimo de Stendhal, desarrolló una gran parte de su obra en Italia (Milán, Parma, Roma), vivió allí y allí ambientó sus obras. Su vida y su obra comparten lo francés y lo italiano. Jarnés y Stendhal confluyen en abundantes recorridos. Éticas y estéticas se (con)funden en determinados momentos en ambos escritores. Jarnés en homenaje al héroe romántico stendhaliano de Le Rouge et Le Noir, escribe Lo Rojo y lo azul, en asombroso paralelismo entre ambos personajes protagonistas.

Jarnés se interesó por la literatura china, versionó los Cuentos del Liao Zhai del escritor chino Pu Songling del siglo XVII: La niña en venta, Estrella errante, Las ruinas mágicas. Probablemente los leyó en una traducción italiana. Identidades e inquietudes literarias compartidas, con las que Jarnés creó un mundo de ilusión en el lenguaje de las hadas y los gnomos, poblado de ondinas que hablan de

\footnotetext{
${ }^{4}$ Los años veinte constituyen la época dorada de las biografías noveladas y en España es Jarnés el cultivador más notable de este género, a través de la Revista de Occidente. Las biografías románticas que Benjamín Jarnés escribió en la serie de Vidas españolas del siglo XIX fueron cuatro: Sor Patrocinio, Zumalacárregui, Castelar y Bécquer.

${ }^{5}$ Véase mi reciente publicación sobre el tema, libro de homenaje a Jean Giraudoux en el que, entre otros aspectos, se recogen numerosos textos escritos por sus contemporáneos: Giraudoux au regard de ses contemporains (Luengo Gascón y Nier, dirs., 2014).
} 
justicia y de amores infantiles. De nuevo, Jarnés se presenta como teórico, crítico y autor de Literatura para niños.

\section{El libro de oro de los niños (un mundo maravilloso para la infancia)}

\section{1. Ediciones de El libro de oro de los niños}

BENJAMÍN JARNÉS: dirección literaria

LUIS DOPORTO: dirección artística

JUANA DE IBARBOUROU Y GABRIELA MISTRAL: prólogos.

ALMA TAPIA et al.: ilustraciones.

$1^{\text {a }}$ Edición: Buenos Aires: U.T.E.H.A. 1943

$2{ }^{\text {a }}$ Edición: Buenos Aires: U.T.E.H.A. 1946

3ª Edición: México, D. F.: Editorial Acrópolis.1949

4ª Edición: México: Acrópolis-U.T.E.H.A. 1951

5ªdición: México.: U.T.E.H.A. 1957.

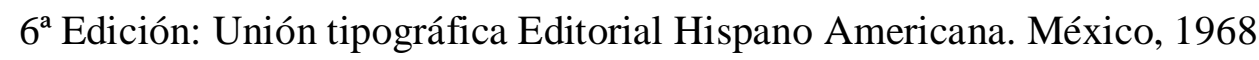

Descripción física: 6 v.: 24,5 x 19,5; il. c.

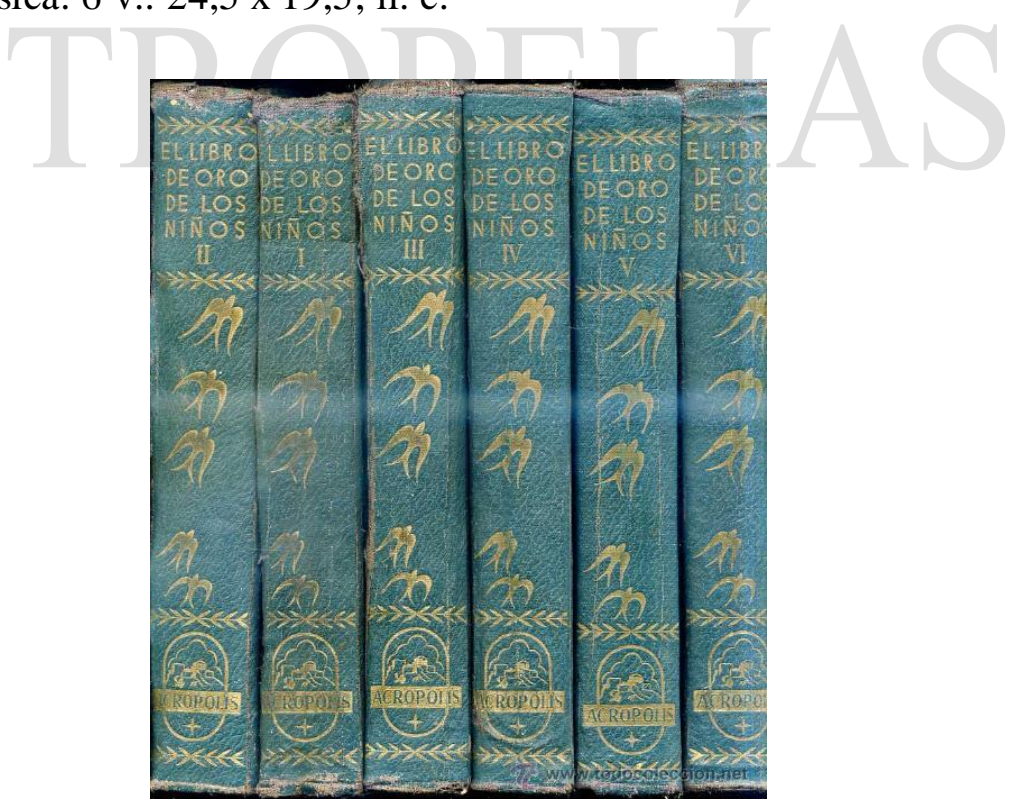

El Libro de Oro de los niños - Seis tomos (1946) Prólogos de Gabriela Mistral y Juana de Ibarborou

Hemos localizado estas ediciones; algunas se encuentran en bibliotecas españolas o centros de lectura y fundaciones, la última (1968), depositada en España la he podido consultar y resulta ser similar a la de $1946^{6}$. Otras se localizan en Hispanoamérica, en coleccionistas, libreros antiguos, etc.

\footnotetext{
${ }^{6}$ Esta edición, de 1946, mantiene los prólogos de Juana de Ibarbouru y de Gabriela Mistral. Jarnés muere en el año 1949 en España. Las ilustraciones de las portadas de cada volumen de las ediciones posteriores cambian considerablemente. Hay que señalar que la edición de 1968 es una reimpresión de la edición de 1946.
} 
Los prólogos de Juana de Ibarbourou y de Gabriela Mistral aparecen en las primeras, son estos datos los que sirven para las notas que a continuación se presentan.

Juana de Ibarbourou en el prólogo general señala:

Tengo en la palma de la mano, para mi hijo, el universo de lo maravilloso. La vida moderna ha jubilado a los magos, pero algunos vuelven a recobrar su poder, y he aquí que nos dan esta avellana mágica. Gira lentamente. Se transforma, se abre, suena a papeles. Y tórnase en una serie de libros con cuanto yo soñaba para mi tierno amor: la fábula, la leyenda, la danza, el cuento, la canción, lo ficticio y lo verdadero. Con el ritmo de las palabras y el ágil color de los lápices, dispongo a mi voluntad del mundo ambicionado. Lo que apenas encontré alguna vez borroso y disperso, está aquí, vivo, rico y accesible. Dialoguemos de nuevo con los duendes". [...] Yo agradezco, por todos mis nietos y bisnietos futuros, esta Biblioteca. ¿Quién la hizo? ¿Un colegio de sabios? No: un conjunto de cerebros lúcidos, de corazones llenos de amor, de inteligencias comprensivas, de artistas traspasados de sentimiento humano [...] En Montevideo, bajo la cruz del Sur, año 1943 (apud Jarnés, dir., 1946: 11-12).

Gabriela Mistral, maestra chilena y premio Nobel de literatura por su labor poética, comenta las ilustraciones en el prólogo: «Lo peor en los libros de niños que he visto durante mis años de maestra eran las ilustraciones. Y es que la cultura artística de los pedagogos ha sido mucho más baja todavía que la literatura» (apud Jarnés, dir., 1946: 13). Gabriela Mistral agradece a la editorial Acrópolis la inversión llevada a cabo en esta empresa:

La Editorial Acrópolis, con una generosidad nunca vista en el gremio, ha gastado enormemente en ilustrar estos volúmenes. La alegría que aquí van a recibir los muchachos, se ha pagado carísima, en dibujantes, en clisés, en papel especial; el gozo que aquí se ofrece a ellos cuesta lo que un parque inglés para juegos (apud Jarnés, dir., 1946: 13).

La escritora habla del arte nuevo, del dibujo y la pintura de vanguardia como agentes beneficiosos para las artes.

Pretendo que el dibujo, y la pintura con más razón, son elementos mucho más preciosos que la literatura en lo que toca a los niños. Retengo hasta hoy todos los grabados de mis libros escolares y, por contraste, he olvidado la mayor parte de los textos. Cosa semejante a esta es la dominación absoluta del cine sobre la literatura. Por lo tanto, la resolución de la Editorial de ilustrar a todo decoro, y también a todo lujo, sus volúmenes para niños, corresponde a un acierto magnífico, a una observación aguda de la infancia (apud Jarnés, dir., 1946: 14).

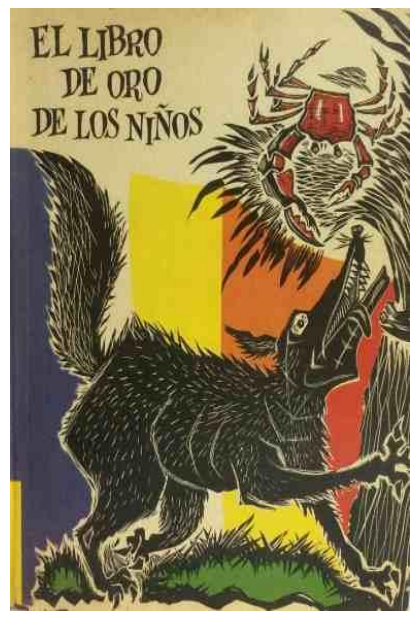

El Libro de Oro de los Niños. Volumen 6 de la reimpresión (1968) de la edición de 1946.

Tirada 5000 ejemplares 


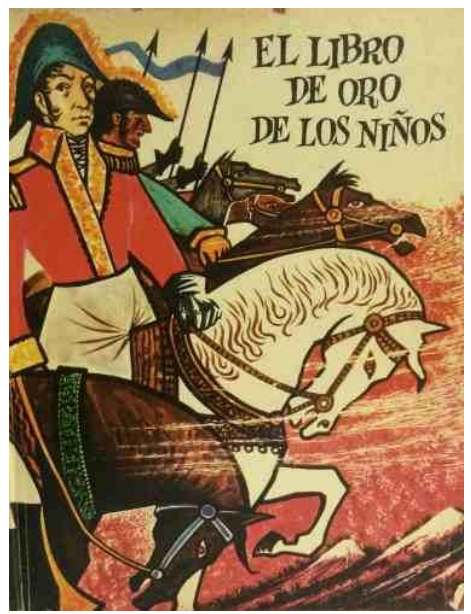

El Libro de Oro de los Niños. Volumen 4 de la reimpresión (1968) de la edición de 1946.

Tirada de 5000 ejemplares

La Enciclopedia consta de seis volúmenes, con un número de páginas entre 260 y 290 cada uno (comenzando por el primer volumen, el número de páginas es el que sigue: 260, 260, 272, 274, 290, 290). Cada volumen se distribuye en diecisiete capítulos con sus respectivos títulos que se mantienen fijos a lo largo de los seis volúmenes.

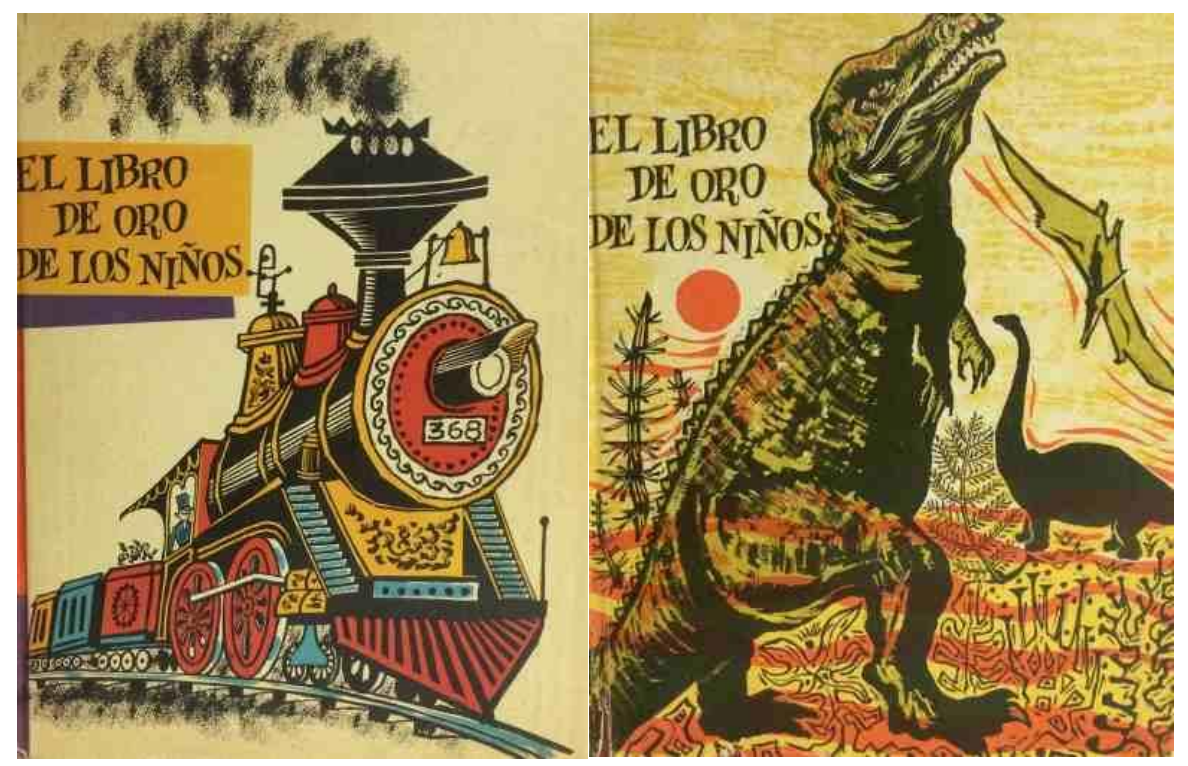

El libro de oro de los Niños. Volúmenes 2 y 3 de la reimpresión (1968) de la edición de 1946. Tirada de 5000 ejemplares

\section{2. Estructura de los capítulos de El Libro de Oro de los niños}

Los diecisiete capítulos van encabezados por un mismo título y un subtítulo que mantienen a lo largo de los seis volúmenes. Comienzan todos con un «Prologuillo» de dos páginas. Los contenidos giran alrededor de un núcleo o centro de interés que se desarrolla desde perspectivas amplias: autores y textos muy variados en la mayor parte de la obra, llamada «Biblioteca» por ambas escritoras. Hemos elegido dos, tres, o cuatro títulos por capítulo como ejemplo. A veces se incluyen hasta veinticinco textos (o secciones, temas, autores, poemas...) en cada capítulo. 
104 Tropelías. Revista de Teoría de la Literatura y Literatura Comparada, 23 (2015)

Elvira Luengo Gascón

\section{3. Contenidos de los capítulos de El Libro de Oro de los niños:}

Cada volumen contiene diecisiete grandes secciones:

1. El ingenio infantil. Diálogos y peripecias

2. La alegría en marcha. El juego

3. Las papirolas. El trabajo manual

4. Al viento y al sol. El campo

5. El mundo sonríe al niño. La poesía

6. Los animales hablan. La fabula

7. Fantasía y realidad. La leyenda y el cuento

8. La vida aventurera. La novela

9. Arriba el telón. El teatro

10. El tapiz mágico. El cine

11. La leyenda aurea de los dioses y de los héroes. La mitología

12. Mirando hacia atrás. La historia

13. El cielo arriba a los hombres. La religión

14. La creación humana. El arte

15. El hombre y la máquina. La industria

16. Maravillas de la naturaleza. La ciencia

17. El mundo mágico de los juguetes

\section{Capítulo I. EL INGENIO INFANTIL} DIÁLOGOS Y PERIPECIAS

Vol.1. Juan sin miedo. Cuestión de confianza. El poeta Arlequín. (24 páginas).

Vol.2. Las metamorfosis. Noches de juguete. El drama del anochecer. El jabón de Arquímedes.

Vol.3. Entre papá y mamá. Idioma internacional. Contrasentidos. Lluvia perdida.

Vol.4. Lo primero, jugar. El buen entendedor. La pura realidad. Estreno fracasado.

Vol.5. La lengua prisionera. Charlot, en el cielo. La quinta sinfonía. La fábula inventada.

Vol.6. Lección astronómica. La media luna. El tiburón, la ballena y la lata. Los nietos de Edison.

\section{Capítulo II. LA ALEGRÍA EN MARCHA}

\section{EL JUEGO}

Vol.1. Ejercicios, juegos. Pasatiempos geográficos.

Vol.2. Adivinanzas de Lope. Acertijos.

Vol.3. Juegos de pensar, del por qué, de correr, de corro.

Vol. 4. El juego de no reírse. 
Vol. 5. Juego de los hoyos. Juego de las palabras. Juego de los refranes.

Vol. 6. El juego de la semana.

\section{Capítulo III. LAS PAPIROLAS.} EL TRABAJO MANUAL

Vol. 1. Regatas. Peces. Papagayo. Pajaritas. Hadas. Construcción del barco.

Vol.2. La rana vanidosa. La ranita amable. Un ratoncito. Plegado de la rana.

Vol.3. La fantasía de gallo. Una cría original. Plegado del gallo.

Vol. 4. El pajarito pardo. Plegado del guacamayo.

Vol. 5. El sueño de Antonio. Diagramas de papirolas.

Vol. 6. El milagro del hada. Los astrónomos y la estrella. El nigromante. El pavo real. Diagramas de papirolas.

\section{Capítulo IV. AL VIENTO Y AL SOL}

\section{EL CAMPO}

Vol.1. El preso libertado. La familia Filandro. El ratón de Eneas.

Vol. 2. Vida de las Termitas. Descripción de la plaga. Paisaje de selva.

Vol. 3. Elefantes y canguros. Vienen las garzas. La soledad del cangurito.

Vol. 4. Castores y pingüinos. Paisaje siberiano. Los enemigos del castor. Ingeniosa arquitectura. Pingüinópolis. La emigración.

Vol. 5. Pinzones y cuclillos. El nido profanado. El mirlo parlamentario.

Vol. 6. Historias naturales: Semblanzas de diferentes animales.

\section{Capítulo V. EL MUNDO SONRÍE AL NIÑO}

\section{LA POESÍA}

Vol. 1. La mocita casadera. El barquero. La pastora. Mambrú se fue a la guerra. La doncella tímida.

Vol.2. El patio de mi casa. La muñeca. Romance de la viudita. La bella raptada. El galán enamorado.

Vol.3. El sueño despierto (J. Martí). El lagarto está llorando (F.G.Lorca). Canción china en Europa (F.G.Lorca). Romance de la niña negra (Luis Cané). Castilla (Manuel Machado).

Vol. 4. Naturaleza viva (F. Luján). El huerto de doña Ana (F. Luján).

Vol. 5. Elegía de la niña y su rosal. Invierno. Río Torres. El caracol, la luciérnaga y el grillo.

Vol. 6. Amanece en Belén (Lope de Vega). Toque de Alba (L. de Góngora). Mañanica en el hielo (Lope de Vega). La flor y la miel (L. de Góngora). 


\section{Capítulo VI. LOS ANIMALES HABLAN}

\section{LA FÁBULA}

Vol. 1. El gallo victorioso (La Fontaine).

Vol. 2. El cangrejo astuto (Esopo). El almendro feliz (G. Civinini).

Vol. 3. La Fontaine.

Vol. 4. La Fontaine. Esopo.

Vol. 5. La Fontaine. Fedro. Esopo.

Vol. 6. La Fontaine. Fedro. Esopo.

\section{Capítulo VII. FANTASÍA Y REALIDAD}

\section{LA LEYENDA Y EL CUENTO}

Vol. 1. Los pájaros (A. Berquin). El guía ciego (G. Gozzi). Historia de una Pluma (Walesca Paixao).

Vol. 2. La casa de las hadas (G. Deledda). La sopa de piedras (Walda Paixao).

Vol. 3. El viejo molinero (A. Daudet). Perla, el elefante (R. Kipling). Rosa-Blanca y Rosa-Roja (Grimm). El gato con botas (C. Perrault).

Vol. 4. La maga de los enanos (Leyenda popular alemana). Los tres regalos del hada (Cuento popular italiano). La camita con ruedas (Storm).

Vol. 5. La fortuna (L. Tolstoi). El moño de la alondra (Leyenda hebrea). La princesa que perdió el color de sus ojos (C. Rodríguez-Pintos).

Vol. 6. El caballero del Thun (Leyenda suiza). Las razas humanas (Leyenda india). El tesoro del bosque (J.C. Schmid). El monito color de rosa (Collodi).

\section{Capítulo VIII. LA VIDA AVENTURERA LA NOVELA}

Vol. 1. Pinocho. El deseo. La isla del placer. La tristeza de Geppeto. La libertad.

Vol. 2. Bertoldo comienza sus hazañas. La revolución de las mujeres. La reina de los estacazos.

Vol. 3. Viajes de Gulliver. Entre los pigmeos. La comida del gigante. Al revés de Liliput.

Vol. 4. Pirulo entre las fieras. En el Polo Norte. Un torbellino polar. Viaje submarino.

Vol. 5. El asno de oro (L. Apuleyo). El muerto resucitado. El fin de Espartaco. El asno en la mesa.

Vol. 6. Los oficios de Tomasín. Tomasín en la fragua. Marinero y constructor.

\section{Capítulo IX. ARRIBA EL TELÓN}

\section{EL TEATRO}

Vol. 1. Pulgarcito (C. Perrault): Comedia en tres actos. 
Vol. 2. Cenicienta (C. Perrault): Monólogo en un acto con prólogo y epílogo.

Vol. 3. Caperucita roja: Comedia fantástica en tres actos.

Vol. 4. El sueño de Natacha (Juana de Ibarbourou): comedia fantástica en un acto.

Vol. 5. La bella durmiente del bosque (C. Perrault): Comedia en tres actos y un prólogo.

Vol. 6. Blanca Nieves y los siete enanitos: Tragicomedia en tres actos y un prólogo.

\section{Capítulo X. EL TAPIZ MÁGICO}

EL CINE

Vol. 1. Lección de baile: Película

Vol. 2. Aventuras de un joven pegaso: Película.

Vol. 3. Pluto y su protegido: Película.

Vol. 4. El grillo orador: Película. Vol. 5. Viento y globos: Película.

Vol. 6. El patito feo: Película (J. C. Andersen)

\section{Capítulo XI: LA LEYENDA AUREA DE LOS DIOSES Y DE LOS HÉROES LA MITOLOGÍA}

Vol. 1. Hércules. La cierva de cuernos de oro. El toro de Creta. Deyanira y el centauro.

Vol. 2. El nacimiento de Venus y la caja de Pandora. Destierro de Vulcano.

Vol. 3. Un desafío en la corte del rey Midas. El sátiro Marsias.

Vol. 4. La diosa Luna. La predicción de las Parcas. Nacimiento de Atalanta. El castigo de Diana.

Vol. 5. Faetón el temerario. La familia de Apolo.

Vol. 6. Origen mitológico del mundo. Cíclopes y titanes. El monte Olimpo. El castigo de Aracné.

\section{Capítulo XII. MIRANDO HACIA ATRÁS}

\section{LA HISTORIA}

Vol. 1. Simón Bolívar. El paso de los Andes. Bocayá y Carabobo.

Vol. 2. Benito Juárez. José Martí. Martí revolucionario.

Vol. 3. Independencia del Perú. Destierro voluntario. Escritor y revolucionario.

Vol. 4. La familia Colón. De rey en rey.

Vol. 5. Una reina de seis años. Una niña en el trono. La comisión de hombres feroces.

Vol. 6. Un niño llamado Franklin. Escritor infantil. 


\section{Capítulo XIII. EL CIELO MIRA A LOS HOMBRES}

\section{LA RELIGIÓN}

Vol. 1. La última cena.

Vol. 2. De Saulo a San Pablo.

Vol. 3. El niño perdido.

Vol. 4. La heroína de Betulia.

Vol. 5. De Egipto a Palestina.

Vol. 6. El diluvio y el arca.

\section{Capítulo XIV. LA CREACIÓN HUMANA}

\section{EL ARTE}

Vol. 1. Arte egipcio, asirio, dórico, romano, bizantino... arte moderno.

Vol. 3. El arte. "Cuándo y por qué".

Vol. 4. Primores de la vieja España. La dama de Elche.

Vol. 5. Primeras artes. Primeras tallas. El primer pintor. Artistas primitivos de hoy.

Vol. 6. El arte en las ventanas. Ventanas árabes y bizantinas. Ventanas románticas.

La ventana barroca... Arquitectura moderna.

\section{Capítulo XV. EL HOMBRE Y LA MÁQUINA}

\section{LA INDUSTRIA.}

Vol. 1. El carbón. El fuego interior. El diamante negro. La aldea minera.

Vol. 2. El poder de la máquina. El hombre maquinizado. Porvenir feliz.

Vol. 3. La arena y la arcilla. Caolín en Europa. Las porcelanas. Calidad y altos precios.

Vol. 4. Visita al herrero. Altos hornos. La fragua del diablo.

Vol. 5. Historia del tren. Elegía de la diligencia. Triunfo del ferrocarril.

Vol. 6. El poema del pan. Historia del pan. El pan en el horno.

\section{Capítulo XVI. MARAVILLAS DE LA NATURALEZA LA CIENCIA.}

Vol. 1. Ascensiones a la estratosfera. La atmósfera. Su majestad el sol.

Vol. 2. La gravitación universal. El columpio de Colorín.

Vol. 3. Una excursión por la edad primaria.

Vol. 4. La Edad de la Tierra. Colorín y su perro. Aparece nuevamente Merlín.

Vol. 5. Una excursión por el sistema solar. El sueño de Colorín. Aparece el Mago Merlín.

Vol. 6. La mejor máquina fotográfica. Animales sin ojos. 


\section{Capítulo XVII. EL MUNDO MÁGICO DE LOS JUGUETES}

Vol. 1. Juguetes clásicos y modernos. Niñas y niños juegan a su modo.

Vol. 2. Los delfines.

Vol. 3. ¡Vamos al parque!

Vol. 4. El hombre y sus amigos salen al Cosmos.

Vol. 5. MADURODAM, la maravillosa ciudad de los niños. “...El increíble mundo donde los niños y los adultos vuelven a ser hermanos".

\section{Conclusión}

Las enciclopedias para niños han ejercido una importante función en la construcción de la identidad de los jóvenes lectores. Tanto la imagen como los textos y los modelos propuestos van configurando unos modos de ser. La función lúdica constituye un elemento crucial y necesario en el desarrollo de la imaginación, de la fantasía y de la creatividad. El recorrido de las diferentes enciclopedias presentadas que se entrecruzan en Europa resulta esclarecedor por la confluencia de temas entre unas y otras. La ilustración, a su vez, goza de un gran auge, se seleccionan grandes artistas para acompañar a los textos y encontramos sus imágenes en unas y en otras enciclopedias traspasando fronteras. La literatura Infantil y Juvenil se ha visto representada en estas obras desde perspectivas innovadoras que escapan a las constricciones políticas y a las ideologías bélicas de los periodos de guerras y entreguerras europeos. Los movimientos políticos, el exilio y las guerras han mantenido una proyección entre países favoreciendo las transferencias de estas obras, de los autores y artistas. Hispanoamérica recoge la tradición europea y proyecta a su vez sus mejores logros literarios. Podemos hablar de identidades nacionales e individuales, sin embargo, en la era de la globalización, de las bibliotecas virtuales y del conocimiento digital, resulta extraño creer en grandes diferencias identitarias. La literatura Infantil y Juvenil, o la literatura sin adjetivos, recordando a Andruetto, se traduce a todos los idiomas y los modelos que proporciona el mercado editorial no encuentran fronteras.

Recordemos, como aprendizaje, las obras de calidad del pasado reciente para seleccionar aquellas que el presente ofrece y poder superarlas.

\section{Referencias bibliográficas}

AIOLFI, G. (2007): La Scala d'oro della UTET: una collana per ragazzi durante il fascismo (1932-36). Milán. Università degli studi di Milano.

Andruetto, M. T. (2009): Hacia una literatura sin adjetivos. Córdoba, Comunicación-Arte.

Ahumada ZuAZA, L. (2015): «Teatro Infantil y Juvenil Español. Las vanguardias del siglo XX», Cuadernos de Literatura Infantil y Juvenil (CLIJ), 263 (enero-febrero), pp. 16-28.

BASANTA-REYES, A. (2005). «La pasión de leer», Revista de Educación, número extraordinario 1, pp. 189-201. 
110 Tropelías. Revista de Teoría de la Literatura y Literatura Comparada, 23 (2015)

Elvira Luengo Gascón

Cerrillo Torremocha, P. C., y Miajas, M. T., coords. (2013): La literatura infantil y juvenil española en el exilio mexicano. Cuenca, Universidad de Castilla La Mancha.

Cervera, J. (1992): «La contribución hispanoamericana al desarrollo del estudio de la literatura infantil en España», Cauce, 14-15, pp. 297-305.

Colomer, T. (1991): «Últimos años de la literatura infantil y juvenil. Desde el mayo del 68 a la postmodernidad de los ochenta», Cuadernos de la literatura Infantil y Juvenil (CLIJ), 26 (marzo), pp. 14-26.

ERrante, V., y PALAZZI, F. (1932): La Scala d'oro. Torino, UTET.

HACHE-BisSETTE, F. (2002): «Découvertes Gallimard ou la culture encyclopédique à la française», en J. Marseille et P. Eveno, dirs., Histoire des industries culturelles en France XIX ${ }^{e-X X} X^{e}$ siècles, París, ADHE, pp. 111-124. Tb. en http://www.ricochet-jeunes.org/articles-critiques/article/78decouvertes-gallimard-ou-la-culture-encyclop (última consulta, 20-1-2015).

(2008): «Vulgarisation, "non-fiction" et littérature documentaire: apprendre avec ou sans la littérature, des premiers manuels aux "documentaires" actuels», en AA. VV., Babar, Harry Potter et compagnie. Livres d'enfants d'hier et d'aujourd'hui. París, Bibliothèque Nationale de France, pp. 356-361.

JARNÉS, B., dir. lit. (1946): El libro de oro de los niños (un mundo maravilloso para la infancia) México, UTEHA.

LARROSA, J. (1996): La experiencia de la lectura estudios sobre literatura y formación. Barcelona, Laertes.

LUENGO GASCON, E., y NIER, C., dirs. (2014): Giraudoux au regard de ses contemporains. Hommages. Cahier Jean Giraudoux 42. Clermont-Ferrand, Presses Universitaires Blaise Pascal.

MEE, A., trad. y adapt. (1920): L'Enciclopedia dei ragazzi. Milán, Mondadori.

MÈLICH, J. (2006): «El trabajo de la memoria o el testimonio como categoría didáctica», Enseñanza de las ciencias sociales. Revista de Investigación, 5, pp. 115-123.

RODARI, G. (2002): Gramática de la fantasía. Barcelona, Planeta.

Pelegrín, A., Sotomayor, M. V., y Urdiales, A., eds. (2008): Pequeña memoria recobrada. Libros infantiles del exilio del 39. Madrid. Ministerio de Educación, Política Social y Deporte.

PERriconi, Graciela (2009): «Hacia una literatura sin adjetivos. Maria Teresa Andruetto» (reseña), en http://espaciodelij.blogspot.com.es/2009/07/resenas-lij.html (última consulta, 20-1-2015).

Tiana Ferrer, A. (2008): «Prólogo», en Pelegrín, Sotomayor y Urdiales, eds. (2008), pp. 5-6.

YUBERO, S., y LARRAÑAGA, E. (2010): «El valor de la lectura en relación con el comportamiento lector. Un estudio sobre los hábitos lectores y el estilo de vida en niños», Ocnos, 6, pp. 7-20, en http://www.revista.uclm.es/index.php/ocnos/ article/view/188 (última consulta, 20-1-2014). 